\title{
Medical Image of the Week: Hydropneumothorax
}

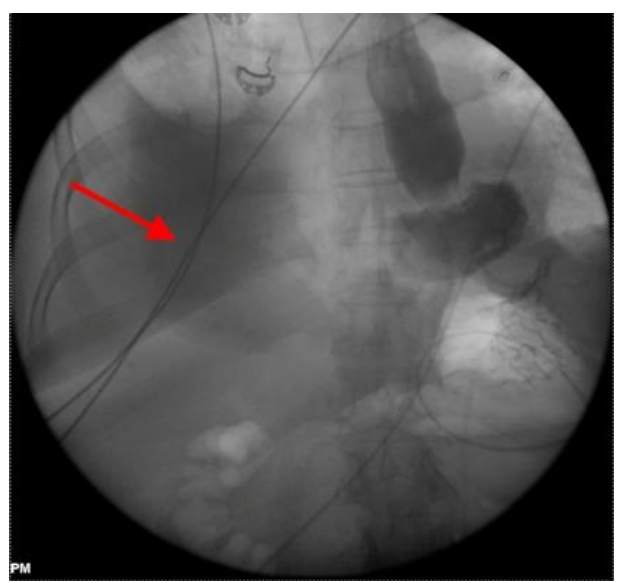

Figure 1. Gastrograffin Esophagram revealing the presence of contrast in the right pleural space (arrow).

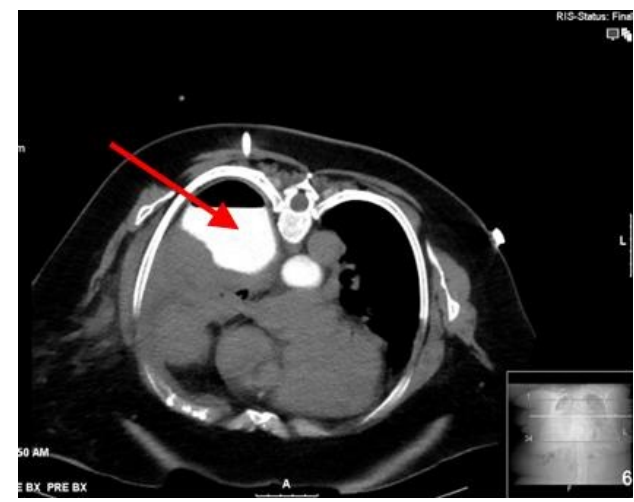

Figure 2. Chest CT revealing right hydropneumothorax containing Gastrograffin. Note the presence of Gastrograffin in the esophagus as well as pleural space (arrow).

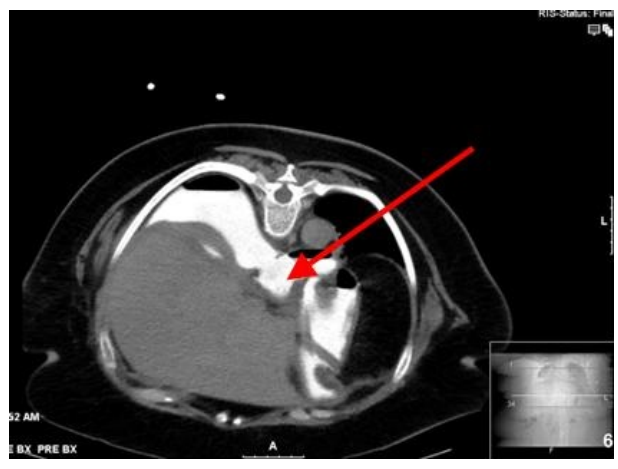

Figure 3. Chest CT showing a communicating channel between the esophagus and right pleural space (arrow). 
A 67-year-old woman who underwent a robotic laparoscopic surgical repair secondary to a large paraesophageal hernia with gastric volvulus. Post-operatively, she developed respiratory distress and a chest CT revealed a large right hydropneumothorax. A Gastrograffin esophagram was done showing Gastrograffin in the esophagus, stomach as well as in the right pleural space suggesting an esophageal-pleural fistula (Figure 1). A chest tube was placed and contrast was present revealing a esophageal-pleural fistula (Figures 2 and 3).

Esophageal perforation should be considered in all patients with unexplained chest pain. Rapid recognition and diagnosis is key as delay in treatment is associated with increased mortality and morbidity (1). Causes of esophageal perforations include upper endoscopy, Boerhaave's syndrome, foreign body ingestion, trauma, malignancy and intra-operative injury (2). Treatment depends on the location and the extent of the perforation as surgical intervention is the gold standard.

Bassel Saksouk MD${ }^{1}$, Choua Thao $\mathrm{MD}^{1}$ and Carmen Luraschi MD ${ }^{2}$

University of Nevada School of Medicine: Las Vegas

${ }^{1}$ Department of Internal Medicine

${ }^{2}$ Division of Pulmonary and Critical Care

Las Vegas, NV

\section{References}

1. Iannettoni MD, Vlessis AA, Whyte RI, Orringer MB. Functional outcome after surgical treatment of esophageal perforation. Ann Thorac Surg. 1997;64(6):1606-9. discussion 1609-10. [PubMed]

2. Bayram AS, Erol MM, Melek H, Colak MA, Kermenli T, Gebitekin C. The success of surgery in the first 24 hours in patients with esophageal perforation. Eurasian J Med. 2015;47(1):41-7. [CrossRef] [PubMed] 